\title{
Neutrophils' functional activity in patients with mechanical jaundice and different levels of bilirubin
}

\author{
Marina A. Darenskaya ${ }^{1, * \odot}$, Liubov I. Kolesnikova ${ }^{1 \oplus}$, Olga V. Smirnova ${ }^{2 \odot}$, Boris G. Gubanov ${ }^{2}$, \\ Edward V. Kasparov ${ }^{2}{ }^{\circledR}$, Sergei I. Kolesnikov ${ }^{1 \circledR}$
}

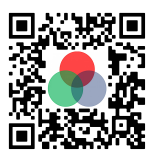

Use your smartphone to scan this QR code and download this article

${ }^{1}$ Scientific Centre for Family Health and
Human Reproduction Problems, 664002 Irkutsk, 16 str. Tymirysev, Russia

${ }^{2}$ Research Institute of Medical Problems of the North Krasnoyarsk Science Center, 660022 Krasnoyarsk, 3 G building 3 str. Partisan Zheleznyak, Russia

\section{Correspondence}

Marina A. Darenskaya, Scientific Centre for Family Health and Human Reproduction Problems, 664002 Irkutsk, 16 str. Tymirysev, Russia

Email: marina_darenskaya@inbox.ru

History

- Received: Mar 13, 2021

- Accepted: Jun 01, 2021

- Published: Jun 30, 2021

DOI : 10.15419/bmrat.v8i6.679

\section{Check for updates}

\section{Copyright}

( $)$ Biomedpress. This is an openaccess article distributed under the terms of the Creative Commons Attribution 4.0 International license.

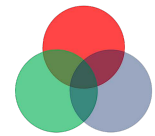

\section{INTRODUCTION}

Mechanical jaundice (MJ) or bile duct blockage (code K83.1, according to ICD 10) is a clinical and morphological manifestation complex that occurs when the bile ducts' patency is impaired, and the bile flow from the liver to the duodenum has stopped ${ }^{1}$. This pathology is detected in $12-45 \%$ of cases of hepatopancreatoduodenal diseases, mainly in men ${ }^{2,3}$. Complications involving $\mathrm{MJ}$ include biliary tract disturbances, dysfunctional liver disorders, and numerous systemic disorders ${ }^{4,5}$. One of the main pathogenetic factors that develop complications with $\mathrm{MJ}$ is immune system imbalance, particularly its phagocytic link ${ }^{6,7}$. This is manifested through phagocytosis process violations, changes in interleukin levels, neutrophil degranulation, and oxidative stress development ${ }^{8-11}$. Neutrophils' functional activity depends on the intensity of the respiratory burst process, and intracellu- lar metabolism ${ }^{12,13}$. The chemiluminescence $(\mathrm{ChL})$ method allows the analysis of the features of a respiratory burst in spontaneous and induced states in various diseases ${ }^{14}$. An extremely important indicator for patients with MJ is their bilirubin level, which plays a crucial role in the disease progression ${ }^{15}$. It has been previously shown that the increased levels of serum bilirubin may be the reason for the bactericidal activity of neutrophils' impairment in patients with hyperbilirubinemia ${ }^{16,17}$. Studying the neutrophils' functioning mechanisms and their relationship with bilirubin levels allow to identify intracellular targets, which makes it possible to modulate the cells' reactivity. Neutrophil dysfunction's detection can contribute to MJ's differential diagnosis and prognosis. In this regard, our work aimed to study neutrophils' functional activity dependence with the bilirubin levels in men with mechanical jaundice. 


\section{METHODS}

\section{Design of the study}

The study used data on men with $\mathrm{MJ}$ ( $\mathrm{n}=47$; mean age $-52.02 \pm 5.18$ years) who were treated at the Research Institute of Medical Problems of the North Krasnoyarsk Science Center. The control group consisted of practically healthy men $(n=50$; average age $-48.7 \pm 3.9$ years) who underwent a routine medical examination. The criteria for inclusion for the clinical and control groups were as follows: male, age 45-59 years, and informed consent to participate in the study.Thecriteriafor exclusion for the groups included the following: severe somatic diseases, including tuberculosis and HIV infection as well as drug addiction, and refusal to participate in the study. The diagnosis of mechanical jaundice (MJ) is based on (determined by) a combination of clinical and diagnostic signs (pronounced pain syndrome, bilirubin levels, alkaline phosphatase levels, liver enzymes levels, liver ultrasound, etc.) and the existence of cholelithiasis. The patients with MJ were divided into three subgroups depending on the bilirubin levels in blood: less than $60 \mu \mathrm{mol} / \mathrm{L}(\mathrm{n}=10), 60-200 \mu \mathrm{mol} / \mathrm{L}(\mathrm{n}=20)$, and more than $200 \mu \mathrm{mol} / \mathrm{L}(\mathrm{n}=17)^{18}$.

\section{Ethics approval for research}

Before beginning the study, the Ethics Committee of the Research Institute of Medical Problems of the North Krasnoyarsk Science Center had approved it (protocol № 7 of November 16, 2012). Ethical principles were observed in accordance with the Helsinki Declaration of the World Medical Association (1964, ed. 2013).

\section{Biochemical measurements}

The neutrophils' functional state was assessed at the time of the patients' admission to the hospital and before therapy. Peripheral blood from the ulnar vein was used. The method of neutrophils' spontaneous and induced luminol-dependent chemiluminescence (ChL) assessing was used ${ }^{19,20}$. ChL was assessed by the biochemiluminescence analyzer BLM-3607 for 90 minutes. The following parameters were analyzed: the time when the curve reached the maximum level of ChL intensity ( $\mathrm{T}$ max spontaneous and $\mathrm{T}$ max induced), the maximum intensity of the $\mathrm{c}$ ChL (I max spontaneous and I max induced), and the square under the curve of spontaneous ChL (S spontaneous) and induced ChL (S induced). Luminol was used as ChL amplifier, and opsonized zymosan served as an inducer of a respiratory burst. We also used the activation index indicator - the ratio of $S$ induced to $S$ spontaneous.

\section{Statistical procedure}

Statistical processing of the material was done using Statistica on Windows 8.0 application software package (Stat SoftInc., USA, 2008), and it included methods for determining the proximity of the sample to the normal distribution law (visual-graphical method, Kolmogorov-Smirnov agreement criteria, and Lilliefors and Shapiro-Wilk tests). The Mann-Whitney rank test was also used to analyze the statistical significance of the revealed differences among quantitative data. The critical significance level was assumed to be $\mathrm{p}<0.05$.

\section{RESULTS}

In the group of patients with MJ and bilirubin levels less than $60 \mu \mathrm{mol} / \mathrm{L}$, there was a statistically significant increase in the values of $\mathrm{T}$ max spontaneous by $96 \%$ ( $\mathrm{p}=0.02$ ), I max spontaneous by $44.81 \%$ ( $\mathrm{p}=$ $0.015), S$ spontaneous by $224.6 \%(\mathrm{p}=0.015), \mathrm{T} \max$ induced by $19.9 \%(p=0.04)$, I max induced by $13.5 \%$ $(\mathrm{p}=0.01)$, and $\mathrm{S}$ induced by $140.3 \%(\mathrm{p}=0.015)$ compared with the control values (Figure 1).

The group of patients with MJ and bilirubin levels from 60 to $200 \mu \mathrm{mol} / \mathrm{L}$ were characterized by a statistically significant increase in $\mathrm{T}$ max spontaneous by $86.8 \%$ ( $\mathrm{p}<0.001$ ), I max spontaneous by $47.7 \%$ ( $\mathrm{p}<$ $0.001)$, S spontaneous by $204,6 \%$ ( $p<0.001)$, I max induced by $28.3 \%$ ( $\mathrm{p}<0.001)$, S induced by $445 \%$ ( $<<$ $0.001)$, and activation index by $70 \%(\mathrm{p}<0.001)$ compared with the control values (Figure 2).

The group of patients with MJ and bilirubin levels more than $200 \mu \mathrm{mol} / \mathrm{L}$ differed as well as the previous group with an increase in the level of $\mathrm{T}$ max spontaneous by $85.9 \%$ ( $\mathrm{p}<0.001)$, I max spontaneous by 53.4 $\%(\mathrm{p}<0.001)$, S spontaneous by $927.3 \%(\mathrm{p}<0.001)$, I max induced by $28.6 \%$ ( $p<0.001$ ), $S$ induced by $1045 \%(\mathrm{p}<0.001)$, and activation index by $92.3 \%$ ( $\mathrm{p}$ $<0.001$ ) compared with the control values (Figure 3 ). The intergroup differences related to S spontaneous, which was higher in the group with bilirubin levels of more than $200 \mu \mathrm{mol} / \mathrm{L}$ compared with the groups with bilirubin levels less than $60 \mu \mathrm{mol} / \mathrm{L}$ by $216.9 \%$ (p $=0.002$ ) and the group with $60-200 \mu \mathrm{mol} / \mathrm{L}$ bilirubin levels by $237.3 \%(\mathrm{p}<0.001)$.

\section{DISCUSSION}

The concept of respiratory refers to the process of increasing the synthesis of reactive oxygen species (ROS) by phagocytic cells, which occurs either during phagocytosis or under regulatory influences ${ }^{21,22}$. Primary and secondary ROS have a moderate bactericidal and regulatory effect and are synthesized 


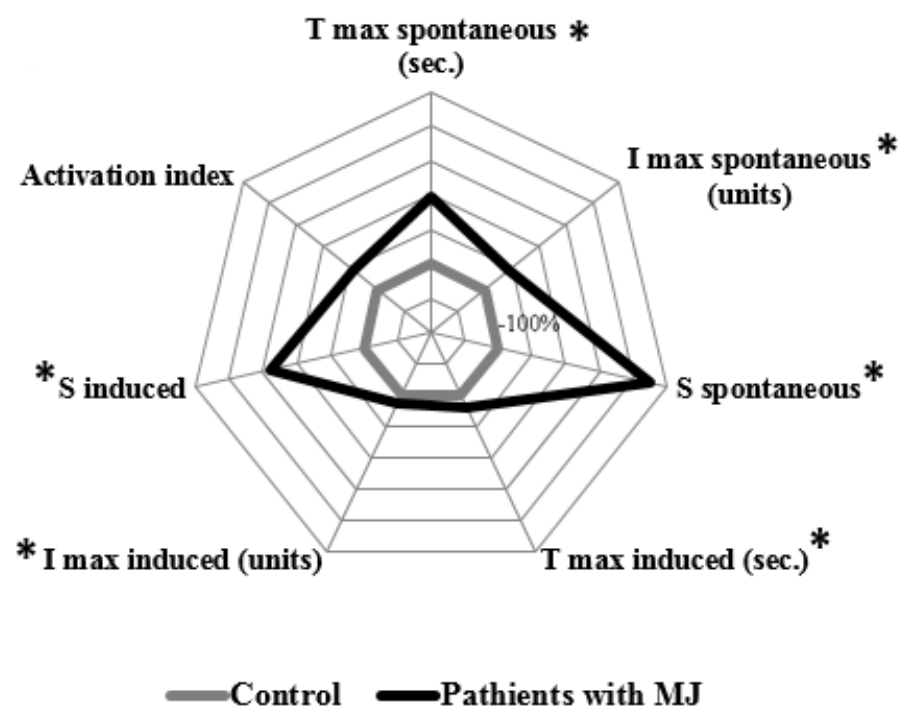

Figure 1: Functional activity indicators of neutrophils in patients with $\mathrm{MJ}$ and bilirubin levels less than 60 $\mu \mathrm{mol} / \mathrm{L}(*$ - statistically significant differences with the control (values taken as $\mathbf{1 0 0} \%)$ ). Legend: I: intensity; Max: maximum; $\mathbf{M J}$ : mechanical jaundice; $\mathbf{S}$ : square; T: time.

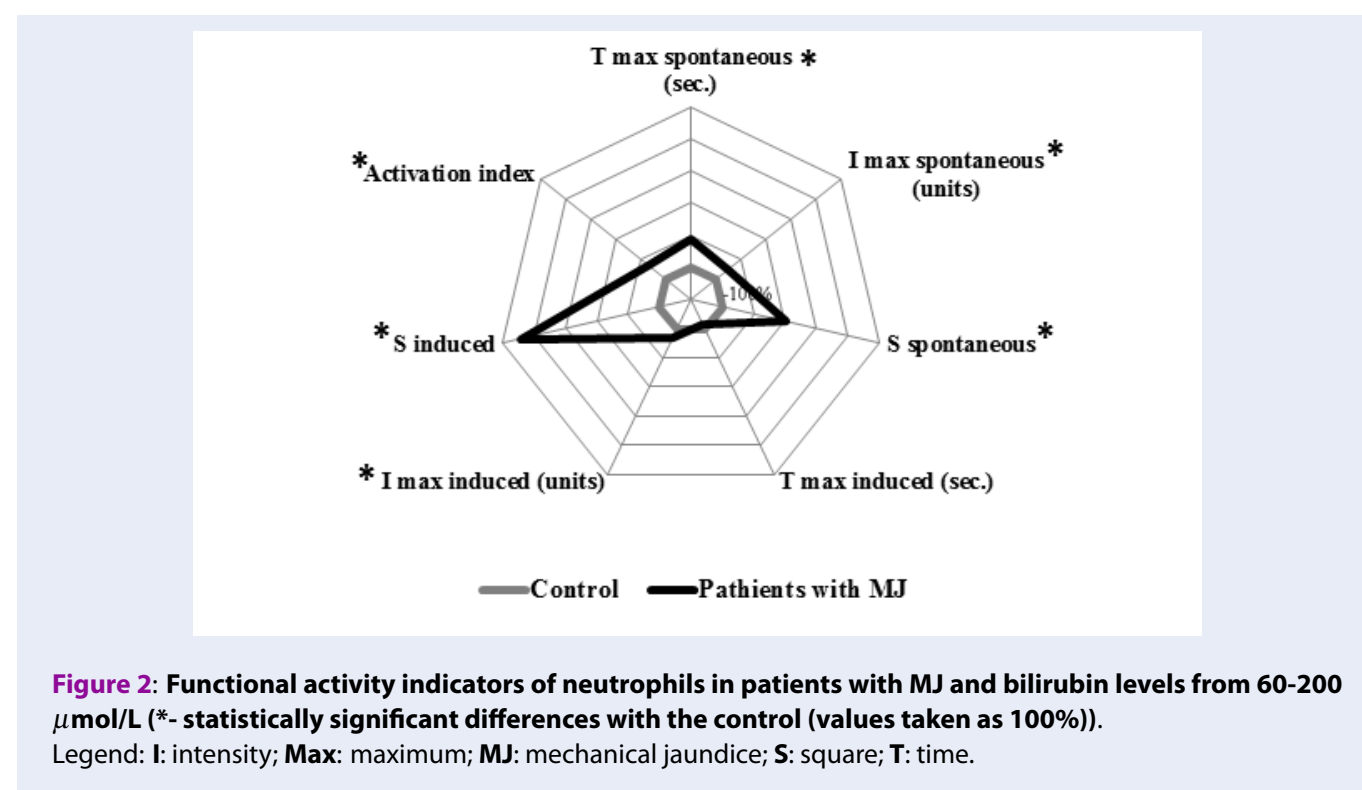




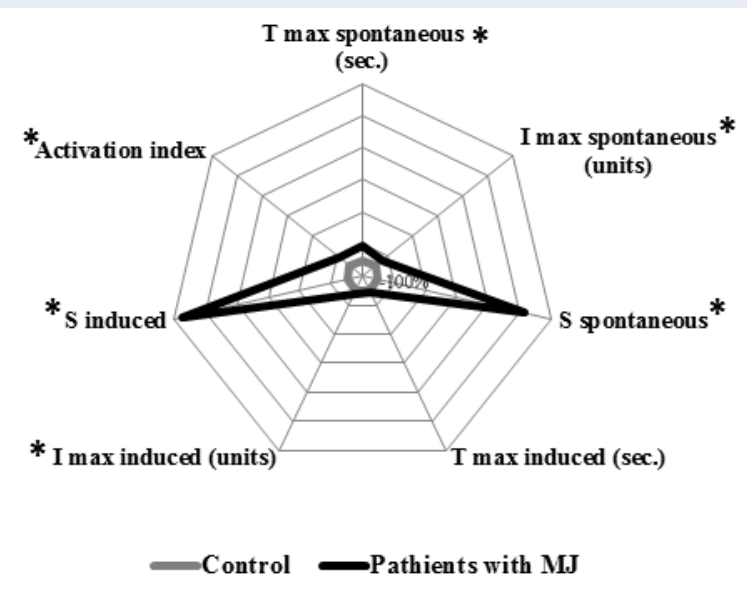

Figure 3: Functional activity indicators of neutrophils in patients with $\mathrm{MJ}$ and bilirubin levels more than

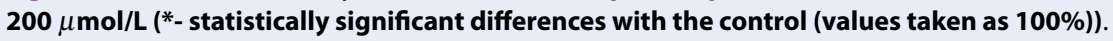
Legend: I: intensity; Max: maximum; MJ: mechanical jaundice; $\mathbf{S}$ : square; T: time.

in cells during enzymatic or non-enzymatic reactions ${ }^{22-26}$. According to the literature, neutrophils' functional activity directly depends on the chemiluminescence's intensity; the higher the chemiluminescence, the greater their functional capacity ${ }^{19}$. Due to the low quantum yield of spontaneous luminescence, special luminescence acceptors, known as indicators, are actively introduced to sensitize luminescence. The ability of one such indicator, luminol, to interact with both primary and secondary ROS determines its inability to be used to assess particular ROS synthesis levels, but it allows us to integrally characterize the state of the respiratory burst of phagocytic cells ${ }^{27}$. In our study, an increase in $\mathrm{T}$ max was observed with spontaneous and induced chemiluminescence in patients with $\mathrm{MJ}$ and bilirubin levels less than $60 \mu \mathrm{mol} / \mathrm{L}$. This indicator reflects the duration for the development of the maximum activity of ROS synthesis from the moment of antigenic induction of phagocytes' respiratory explosion and depends on the state of cells' metabolic reactions ${ }^{12,28}$. Their values, as a rule, decrease in the case of acute infectious and inflammatory diseases when neutrophils are in the activated state and increase in chronic inflammatory processes $^{29-31}$. I max spontaneous and induced, reflecting the maximum synthesis of ROS by the cell, also increases at bilirubin levels below $60 \mu \mathrm{mol} / \mathrm{L}$.

The square under the chemiluminescence curve, which integrally characterizes the entire complex of ROS (S) produced by phagocytes during the study period, changed in a similar way, with the most intense increase in spontaneous chemiluminescence.
The group with bilirubin levels of $60-200 \mu \mathrm{mol} / \mathrm{L}$ was characterized by initial changes related to the control, while there was a tendency for a slight decrease in the values of a number of indicators.

The greatest increase was found in the $\mathrm{S}$ induced parameter, which characterizes the entire phagocytic pool of ROS, and was confirmed by the increase in activation index in this group. Activation index, which is the ratio of $S$ induced to $S$ spontaneous, shows the presence of intracellular metabolic reserves for the implementation of a respiratory burst ${ }^{32}$. The study revealed a significant increase regarding this parameter in patients with $\mathrm{MJ}$ and $60-200 \mu \mathrm{mol} / \mathrm{L}$ bilirubin levels. The group with MJ and more than $200 \mu \mathrm{mol} / \mathrm{L}$ bilirubin levels also showed an increase in indicators related to the control. However, in this group, there was also a significant increase in the values of $S$ spontaneous compared with the group with lower bilirubin levels.

Bilirubin, belonging to bile pigments, is a product of the catabolism of heme-containing compounds and is mainly considered a negative factor in diseases associated with the liver and biliary tract ${ }^{20}$. The toxic effect of elevated bilirubin in blood on patients with $\mathrm{MJ}$ is manifested through the appearance of foci of necrosis in parenchymal organs, suppression of cellular immune response, and other effects ${ }^{21,33}$. The final stage of the pathological process in hepatic parenchyma is the initiation of hypoxic or free radical necrobiosis, subsequently causing cell death ${ }^{1,2}$. Despite the available data on the inhibitory ability of bilirubin in relation to neutrophil activity, we found an increase in 
the total square under the chemiluminescence curve, which characterizes the entire complex of ROS (S spontaneous) produced by phagocytes. This fact can be associated with the benign genesis of the disease, when numerous pathological phenomena can be reversible, in contrast to the tumor process ${ }^{3,8}$.

\section{CONCLUSIONS}

The changes in patients with mechanical jaundice reflect a significant increase in the neutrophils' functional activity in proportion to the bilirubin levels in the blood. These indicators can serve as additional laboratory markers that determine the course of the disease.

\section{ABBREVIATIONS}

ChL: chemiluminescence

I: intensity

Max: maximum

MJ: mechanical jaundice

ROS: reactive oxygen species

S: square

T: time

\section{ACKNOWLEDGMENTS}

None

\section{AUTHOR'S CONTRIBUTIONS}

Research concept and design: Darenskaya MA, Smirnova OV, Kasparov EV

Collection and processing of material: Gubanov BG, Smirnova OV

Text writing: Darenskaya MA, Smirnova OV, Gubanov BG

Editing: Kolesnikova LI, Kasparov EV, Kolesnikov SI Approval of the final version of the article: Kolesnikova LI, Kolesnikov SI

\section{FUNDING}

The work was carried out within the framework of the state budgetary theme.

\section{AVAILABILITY OF DATA AND MATERIALS}

Data and materials used and/or analyzed during the current study are available from the corresponding author on reasonable request.

\section{ETHICS APPROVAL AND CONSENT TO PARTICIPATE}

Not applicable.

\section{CONSENT FOR PUBLICATION}

Not applicable.

\section{COMPETING INTERESTS}

The authors declare that they have no competing interests.

\section{REFERENCES}

1. Pavlidis ET, Pavlidis TE. Pathophysiological consequences of obstructive jaundice and perioperative management. Hepatobiliary Pancreat Dis Int. 2018;17(1):17-21. PMID: 29428098. Available from: 10.1016/j.hbpd.2018.01.008.

2. Khan RS, Houlihan DD, Newsome PN. Investigation of jaundice. Medicine (Abingdon). 2019;47(11):713-7. Available from: 10.1016/j.mpmed.2019.08.011.

3. Zakaria AS, Gamil M, Eldin NHA, Mebed AH. P5: malignant obstructive jaundice; review of 232 Patients. Pan Arab Journal of Oncology. 2019;12(3):55.

4. Papadopoulos V, Filippou D, Manolis E, Mimidis K. Haemostasis impairment in patients with obstructive jaundice. J Gastrointestin Liver Dis. 2007;16(2):177-86. PMID: 17592568.

5. Huynh F, Usatoff V. Obstructive jaundice. Textbook of Surgery. Hoboken (NJ): John Wiley \&amp; Sons Ltd; 2019. Available from: 10.1002/9781119468189.ch67.

6. Hajiyev JM, Taghiyev EG, Hajiyev NJ. ogly Hajiyev JM, oglu Taghiyev EG, oglu Hajiyev NJ. Comparative evaluation of interleukin-6 in the liver tissues, bile duct, blood serum and urine in patients with obstructive jaundice of benign etiology. Journal of Experimental and Clinical Surgery. 2016;9(1):33-8. Available from: 10.18499/2070-478X-2016-9-1-33-38.

7. Shevchenko BF, Zeleniuk OV, Klenina IA, Babii OM. Structural and functional state of the liver in patients with extrahepatic cholestasis of non-tumor genesis. Reports of Morphology. 2019;25(4):36-43. Available from: 10.31393/morphologyjournal-2019-25(4)-06.

8. Darenskaya MA, Smirnova OV, Gubanov BG, Semenova NV, Kolesnikova LI, Kolesnikov SI. Lipid peroxidation, antioxidant defense parameters, and dynamics of surgical treatment in men with mechanical jaundice of various origins. AIMS Mol Sci. 2020;7(4):374-82. Available from: 10.3934/molsci. 2020018.

9. Darenskaya MA, Kolesnikov SI, Rychkova LV, Grebenkina LA, Kolesnikova LI. Oxidative stress and antioxidant defense parameters in different diseases: ethnic aspects. Free Radic Biol Med. 2018;120:60. Available from: 10.1016/j.freeradbiomed. 2018.04.199.

10. Ershova OA, Bairova TA, Kolesnikov SI, Kalyuzhnaya OV, Darenskaya MA, Kolesnikova LI. Oxidative stress and catalase gene. Bull Exp Biol Med. 2016;161(3):400-3. PMID: 27496033. Available from: 10.1007/s10517-016-3424-0.

11. Darenskaya MA, Gavrilova OA, Rychkova LV, Kravtsova OV, Grebenkina LA, Osipova EV. The assessment of oxidative stress intensity in adolescents with obesity by the integral index. Int J Biom. 2018;8(1):37-41. Available from: 10.21103/ Article8(1)_OA5.

12. Proskurnina EV, Dzhatdoeva AA, Lobichenko EN, Shalina RI, Vladimirov YA. Chemiliminescence determination of lipid hydroperoxides in biological fluids. J Anal Chem. 2017;72(7):751-5. Available from: 10.1134/S1061934817050094.

13. Smirnova EV, Krasnova TN, Proskurnina EV, Mukhin NA. Role of neutrophil dysfunction in the pathogenesis of systemic lupus erythematosus. Ter Arkh. 2017;89(12):110-3. PMID: 29411769. Available from: 10.17116/terarkh20178912110-113.

14. Kolesnikova LI, Darenskaya MA, Kolesnikov SI. Free radical oxidation: pathophysiologist's view. Byulleten sibirskoy meditsiny. 2017;16(4):16-29. Available from: 10.20538/1682-03632017-4-16-29. 
15. Uemura S, Higuchi R, Yazawa T, Izumo W, Otsubo T, Yamamoto M. Level of total bilirubin in the bile of the future remnant liver of patients with obstructive jaundice undergoing hepatectomy predicts postoperative liver failure. J Hepatobiliary Pancreat Sci. 2020;27(9):614-21. PMID: 32506707. Available from: 10.1002/jhbp.784.

16. Arai T, Yoshikai $Y$, Kamiya J, Nagino M, Uesaka K, Yuasa N. Bilirubin impairs bactericidal activity of neutrophils through an antioxidant mechanism in vitro. J Surg Res. 2001;96(1):10713. PMID: 11181003 . Available from: 10.1006/jsre.2000.6061.

17. Vagholkar K. Obstructive Jaundice: understanding the pathophysiology. International Journal of Surgery and Medicine. 2020;6(4):26-31. Available from: 10.5455/ijsm.2020-07-061jaundice.

18. Galperin EA, Momunova ON. Classification of the severity of obstructive jaundice. Surgery. Journal them. NI Pirogov. 2014;1:5-9.

19. Lippa S, Sole PD, Meucci E, Littarru GP, Francisci GD, Magalini SI. Effect of general anesthetics on human granulocyte chemiluminescence. Experientia. 1983;39(12):1386-8. PMID: 6653729. Available from: 10.1007/BF01990117.

20. Savchenko AA, Kudryavtsev IV, Borisov AG. Assessment methods and the role of respiratory burst in the pathogenesis of infectious and inflammatory diseases. Infektsiia Immun. 2017;7(4):327-40. Available from: 10.15789/2220-7619-20174-327-340.

21. Winterbourn CC, Kettle AJ, Hampton MB. Reactive oxygen species and neutrophil function. Annu Rev Biochem. 2016;85(1):765-92. PMID: 27050287. Available from: 10.1146/ annurev-biochem-060815-014442.

22. Darenskaya MA, Grebenkina LA, Sholokhov LF, Rashidova MA, Semenova NV, Kolesnikov SI, et al. Lipid peroxidation activity in women with chronic viral hepatitis. Free Radical Biology \& Medicine. 2016;100(S):S192. Available from: 10.1016/j. freeradbiomed.2016.10.525.

23. Kolesnikova LI, Kolesnikov SI, Darenskaya MA, Grebenkina LA, Nikitina OA, Lazareva LM. Activity of LPO processes in women with polycystic ovarian syndrome and infertility. Bull Exp Biol Med. 2017;162(3):320-2. PMID: 28091905. Available from: 10. 1007/s10517-017-3605-5.

24. Kolesnikova LI, Rychkova LV, Kolesnikova LR, Darenskaya MA Natyaganova LV, Grebenkina LA. Coupling of lipoperoxidation reactions with changes in arterial blood pressure in hypertensive ISIAH rats under conditions of chronic stress. Bull
Exp Biol Med. 2018;164(6):712-5. PMID: 29658086. Available from: $10.1007 / \mathrm{s} 10517-018-4064-3$.

25. Kolesnikova LI, Kolesnikov SI, Korytov LI, Suslikova MI, Darenskaya MA, Grebenkina LA. Oxidative stress as a mechanism of reduced glucose absorption under conditions of immobilization stress. Bull Exp Biol Med. 2017;164(2):132-5. PMID: 29177884. Available from: 10.1007/s10517-017-3941-5.

26. Kolesnikova LI, Madaeva IM, Semenova NV, Vlasov BY, Grebenkina LA, Darenskaya MA. Antioxidant potential of the blood in men with obstructive sleep breathing disorders. Bull Exp Biol Med. 2013;154(6):731-3. PMID: 23658909. Available from: 10.1007/s10517-013-2041-4.

27. Bedouhène $S$, Moulti-Mati $F$, Hurtado-Nedelec $M$, Dang PM, El-Benna J. Luminol-amplified chemiluminescence detects mainly superoxide anion produced by human neutrophils. Am J Blood Res. 2017;7(4):41-8. PMID: 28804681.

28. Nakamura M, Umemura K, Hiramatsu M, Oishi H, Maekawa M. Efficacy of stress measurements using salivary ultra-weak chemiluminescence. Traumatology. 2019;67(4):2.

29. Davis RW, Snyder E, Miller J, Carter S, Houser C, Klampatsa $A$. Luminol chemiluminescence reports photodynamic therapy-generated neutrophil activity in vivo and serves as a biomarker of therapeutic efficacy. Photochem Photobiol. 2019;95(1):430-8. PMID: 30357853. Available from: 10.1111/ php.13040.

30. Saqib M, Qi L, Hui P, Nsabimana A, Halawa MI, Zhang W. Development of luminol-N-hydroxyphthalimide chemiluminescence system for highly selective and sensitive detection of superoxide dismutase, uric acid and Co2. Biosens Bioelectron. 2018;99:519-24. PMID: 28823977. Available from: 10.1016/j. bios.2017.08.028.

31. Piknova B, Park JW, Cassel KS, Gilliard CN, Schechter AN. Measuring nitrite and nitrate, metabolites in the nitric oxide pathway, in biological materials using the chemiluminescence method. J Vis Exp. 2016;118(118):e54879. PMID: 28060334. Available from: 10.3791/54879.

32. Su Y, Song H, Lv Y. Recent advances in chemiluminescence for reactive oxygen species sensing and imaging analysis. Microchem J. 2019;146:83-97. Available from: 10.1016/j.microc. 2018.12.056.

33. Redza-Dutordoir M, Averill-Bates DA. Activation of apoptosis signalling pathways by reactive oxygen species. Biochim Biophys Acta. 2016;1863(12):2977-92. PMID: 27646922. Available from: 10.1016/j.bbamcr.2016.09.012. 